\title{
Hollow Fiber Module Applied for Effective Proliferation and Harvest of Cultured Chondrocytes
}

\author{
Yoshiyuki Mori ${ }^{1}$, Makoto Watanabe ${ }^{2}$, Sakae Nakagawa ${ }^{3}$, Yukiyo Asawa ${ }^{2,4}$, Satoru Nishizawa ${ }^{2}$, \\ Kazumi Okubo ${ }^{1}$, Hideto Saijo ${ }^{1}$, Satoru Nagata ${ }^{5}$, Yuko Fujihara ${ }^{2,4}$, Tsuyoshi Takato ${ }^{1,4}$, \\ Kazuto Hoshi ${ }^{1,2,4^{*}}$
}

${ }^{1}$ Department of Sensory and Motor System Medicine, Graduate School of Medicine, The University of Tokyo, Tokyo, Japan; ${ }^{2}$ Department of Cartilage \& Bone Regeneration (Fujisoft), Graduate School of Medicine, The University of Tokyo, Tokyo, Japan; ${ }^{3}$ Nomura Unison Co., Ltd, Nagano, Japan; ${ }^{4}$ Division of Tissue Engineering, The University of Tokyo Hospital, Tokyo, Japan; ${ }^{5}$ NAGATA Microtia and Reconstructive Plastic Surgery Clinic, Saitama, Japan.

Email: "pochi-tky@umin.net

Received July $2^{\text {nd }}, 2013$; revised July $31^{\text {st }}, 2013$; accepted August $7^{\text {th }}, 2013$

Copyright (C) 2013 Yoshiyuki Mori et al. This is an open access article distributed under the Creative Commons Attribution License, which permits unrestricted use, distribution, and reproduction in any medium, provided the original work is properly cited.

\begin{abstract}
Steady and useful culture for chondrocytes is essential for cartilage regenerative medicine. However, in conventional plate culture, the chondrocytes become dedifferentiated and lose their ability to make cartilage matrices. Three-dimensional culture mimicking the physiological environment in native chondrocytes is useful to maintain the chondrocyte properties during the proliferation culture. However, the three-dimensional culture is practically a hard task due to difficult harvest of the cells. Thus, we attempted to apply porous materials, hollow fibers for the three-dimensional culture, and developed their module to realize the effective harvest of the cells. Polyethersulfone-based hollow fibers, whose safety and cell affinity were confirmed by the experiment of the coculture with human chondrocytes, were collected to fabricate a module. The hollow fiber module was installed with screw ends, and enabled the easy removal of chondrocytes from the inner unit. Cultured human chondrocytes embedded within collagen hydrogel were put into the outer lumen of the hollow fiber module, while chondrocyte prolfieration medium was perfused through the inner lumen at 0 to $30 \mathrm{~mL} / \mathrm{min}$. After 2 weeks' culture, the flow rate of 3 to $10 \mathrm{~mL} / \mathrm{min}$ effectively supported the chondrocyte proliferation. Then, long-term culture using the hollow fiber module at flow rate of $5 \mathrm{~mL} / \mathrm{min}$ was performed, revealing that the cell growth in this module at 3 weeks was approximately twice larger than that in static culture. The numbers of viable cells could be maintained by week 7 . The hollow fiber module installed with screw ends can effectively culture and harvest the chondrocytes.
\end{abstract}

Keywords: Hollow Fiber Module; Proliferation; Cell Culture; Chondrocyte; Tissue Engineering

\section{Introduction}

Regenerative medicine has already been practically used in the fields of skin or cartilage treatment and clinically applied worldwide [1,2]. Also for other organs, the application to general medical care, which would be beneficial for many patients and may be theoretically realizable, has been underway. One of the necessities to promote regenerative medicine is the establishment of efficient cell culture techniques. Various animal cells have been cultured in dishes and flasks and contributed to the analysis of cell functions and pharmacological evaluation of drugs. However, these are generally static and mono-

${ }^{*}$ Corresponding author. layer cultures, being totally different from the three-dimensional physiological conditions in the body. The physiological characteristics of cells are lost in artificial environments, such as monolayer culture. For example, although chondrocytes produce abundant cartilage matrices, such as type II collagen and proteoglycan, under physiological conditions, these are not expressed in monolayer culture at all [3]. Moreover, the space in conventional vessels for the monolayer culture is limited and insufficient for massive cell growth. Thus, it is necessary to develop a three-dimensional culture method to cultivate cells under more physiological conditions and efficiently grow and harvest them.

With the recent development of gene recombination 
and hybridoma techniques, the production of various human bioactive proteins including interferon and erythropoietin by cell culture has become possible, and various mass culture techniques have been developed for the mass production of these as pharmaceutical ingredients $[4,5]$. However, these mass cell culture techniques utilize cultured cells as a means of producing medicinal drugs, and, even though cells can be grown in a large quantity and maintained for a certain period, the techniques lack the viewpoint of harvesting the cells that are keeping the original functions, which is inappropriate for regenerative medicine.

For the purpose of maintaining the properties and functions of chondrocytes during the culture, a threedimensional environment similar to the physiological condition in the body may be favorable. For the chondrocytes, a three-dimensional embedded culture method using collagen hydrogel is proposed, because they are surrounded by abundant collagen matrix in the body [6,7]. Otherwise, no culture method capable of efficiently changing the medium and harvesting grown cells without damaging them has been established. The objective of the present study was to develop the three-dimensional culture technique for chondrocytes capable of readily harvesting cultured cells in consideration of cartilage regenerative medicine. For that, we attempted efficient substance exchange under the condition of collagen hydrogel-embedded three-dimensional culture by passing porous materials, hollow fibers in the culture and circulating culture medium through the fibers. To realize this system, the hollow fibers were modularized, and a structure to readily harvest cultured cells was added. This hollow fiber module was prepared for the three-dimensional culture of chondrocytes, and the cell growth in usage of this module was evaluated.

\section{Materials and Methods}

\subsection{Preparation of Hollow Fiber Module}

The hollow fiber module (Nomura Unison, Chino, Japan) was comprised of polyethersulfone (PES) hollow fibers (inner $\varphi$ : $0.3 \mathrm{~mm}$, outer $\varphi$ : $0.5 \mathrm{~mm}$, pore size: $0.2 \mu \mathrm{m}$, Figure 1) fixed in cylindrical housing, and the inner space of the hollow fibers (lumen) and outer space (ECS) were separated by a sealing material (Figure 2 top and middle). Two tube connections (ports) each were prepared in the ECS and lumen to inject cell suspension and circulate culture medium, respectively. One module contained 394 hollow fibers. The module had a structure enabling the efficient harvest of cells grown in ECS. The external form was comprised of a hollow fiber bundle, housing column accommodating the hollow fiber bundle, and screw caps. The housing column was a double tube, in which the inner tube (inner housing) was fixed into the outer tube (outer housing) using an O-ring seal. The hol-

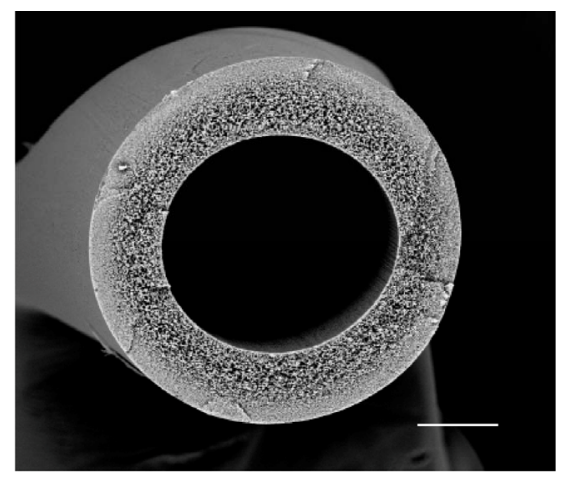

Figure 1. Fine structure of polyethersulfone hollow fibers. The cross-sectional surface of polyethersulfone hollow fibers was observed under SEM. Bar $=100 \mu \mathrm{m}$.
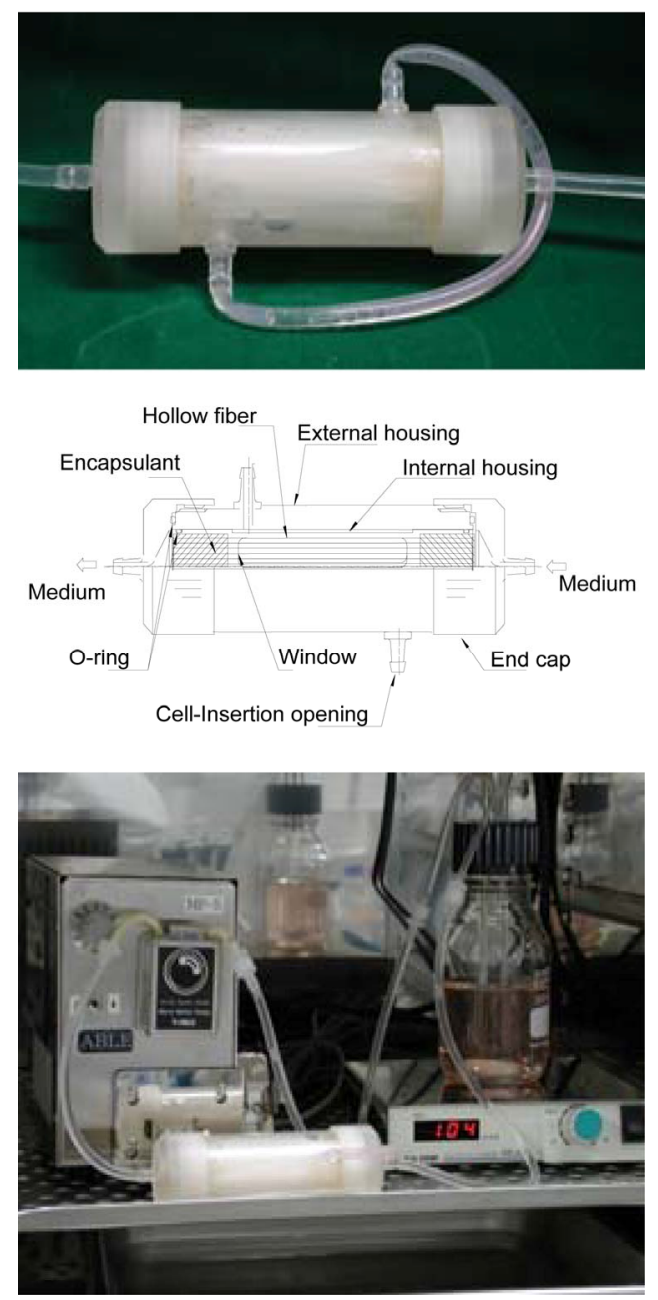

Figure 2. Specification and use method of the hollow fiber module. The hollow fiber module contains 394 hollow fibers, and the volumes of the inner space of the hollow fibers (lumen) and outer space (ECS) were $20 \mathrm{~mL}$, respectively. There were two ports each connected to the lumen and ECS (4 ports in total). Culture medium was circulated through the ports connected to the lumen to grow cells in ECS. The external appearance (top), design (middle), and use (bottom) of the hollow fiber module were shown. 
low fibers were fixed to the inner housing with glue. Openings are appropriately made in the lateral sides of the inner housing to enable culture medium and cells to readily move between ECSs in the inner and outer housings (Figure 2). Since larger openings are convenient on the assumption of cell harvest after culture, openings were made while leaving a minimal framework for maintaining the structure (Figure 2 top and middle). Culture medium was circulated in the lumen and it leaked into ECS through the porous hollow fibers, replacing cellular substances. Since cells cannot pass through the hollow fiber pores, no leakage of cultured cells into the circulating culture medium occurs. After the completion of culture, the caps were opened, the sleeve was pulled out from the outer housing, and cells in ECS were collected.

\subsection{Isolation and Preparation of Chondrocytes}

All experimental procedures were approved by the Ethics Committee of the University of Tokyo Hospital (approval No. 622). After obtaining informed consent, the perichondrium was detached from about 2 - $3 \mathrm{~g}$ of residual auricular cartilage excised from microtia patients using a scalpel and cut into $1 \mathrm{~mm}^{3}$ pieces. These were incubated in $0.15 \%$ collagenase (Wako Pure Chemical Industries, Osaka, Japan) solution at $37^{\circ} \mathrm{C}$ for 24 hours. The lysate was filtered through a cell strainer with a 100 $\mu \mathrm{m}$ pore size to remove residues, and centrifuged at 500 $\mathrm{x} \mathrm{g}$ for 5 minutes to isolate human chondrocytes [8].

The isolated chondrocytes were seeded in a collagen type I-coat plastic tissue culture dish at a density of 2500 cells $/ \mathrm{cm}^{2}$, and cultured in chondrocyte growth medium (DMEM/F-12 containing 5\% human serum, $100 \mathrm{ng} / \mathrm{mL}$ FGF-2, and $5 \mu \mathrm{g} / \mathrm{mL}$ insulin, Fuji Soft, Yokoyama, Japan) in a $37^{\circ} \mathrm{C} / 5 \% \mathrm{CO}_{2}$ incubator $[9,10]$. The medium was changed twice a week. Cells were treated with trypsinEDTA solution and passaged before reaching confluence. After passage, the cells were collected and subjected to experiments.

\subsection{Perfusion Culture of Chondrocytes Using the Hollow Fiber Module}

In the hollow fiber module, $300 \mathrm{~mL}$ of the chondrocyte growth medium was perfused through the lumen, and a gel mixture of chondrocytes $(20,000$ cells $/ \mathrm{mL})$ embedded within $0.3 \%$ atelocollagen (Koken, Tokyo, Japan) was injected into ECS. The cells were cultured at $37^{\circ} \mathrm{C}, \mathrm{pH} 7$, and $20 \%$ oxygen tension.

Caps at both ends of the hollow fiber module were removed, the mixture of cultured cells and atelocollagen hydrogel was aseptically harvested, and cells were recovered by collagenase treatment. The recovered cells were reacted with $200 \mu \mathrm{L}$ each of lysate and fixation buffers (Chemometec, Gydevang, Denmark), while the cells were counted using a NucleoCounterTM (Chemometec) [11].

\section{Results}

Cell affinity of the hollow fibers was investigated by culturing human cultured auricular chondrocytes in a dish containing autoclaved PES hollow fibers on the bottom (Figure 3). Cells did not avoid the fibers, and densely grew in regions close to them, confirming that the hollow fibers were possessed sufficient affinity for the cells.

The hollow fiber module was prepared using 394 hollow fibers (Figure 2 top). The ECS volume in this hollow fiber module was $20 \mathrm{~mL}$, and a structure readily enabling the harvest of cultured cells was added (Figure 2 top and middle). There were 4 ports in total, and 2 ports each could be connected on the lumen and ECS sides. A mixture of chondrocytes and collagen hydrogel was injected into ECS using the 2 ports on the ECS side, and the ports were closed before perfusion culture. The other 2 ports were used to flow culture medium into the lumen to grow cells. The photograph shown in Figure 2 (bottom) showed the actual cell circuit.

Using this hollow fiber module, a flow rate at which hydrogel could be retained and cells could be grown was investigated. Three flow rates were set: low, middle, and high speeds (3, 10 and $30 \mathrm{~mL} / \mathrm{min}$, respectively), and cell growth was compared with that in static culture (Figure 4, flow rate: $0 \mathrm{~mL} / \mathrm{min}$ ). At 2 weeks of culture, the cell count was increased by 4 times in static culture, and 6 times in perfusion culture at the low and middle flow rates (Figure 4). At the high speed, retention of the circuit was difficult because the pressure in the circuit excessively rose and the tubes came off (Figure 4, 30 $\mathrm{mL} / \mathrm{min})$.

When cell growth in culture at a $5-\mathrm{mL} / \mathrm{min}$ flow rate, at which cells grew stably, was compared with that in static culture, growth reached a plateau around 6 weeks and approximately 20,000-30,000 cells (increase by approximately 15 times) were grown in static culture, whereas approximately 60,000 cells were grown using the hollow fiber module (increase by approximately 30 times), 2 times more cells than those in static culture, suggesting that this culture system more efficiently promoted cell growth compared to static culture, and the recovery efficiency was sufficient (Figure 5).

\section{Discussion}

Mass culture of mammalian adhesive cells using a bioreactor requires overcoming limitations different from those in microbial culture. For example, some carriers to support their adhesion are needed using a bioreactor [12]. Protection against physical damage by aeration and stirring is also necessary [13]. Various culture devices and 


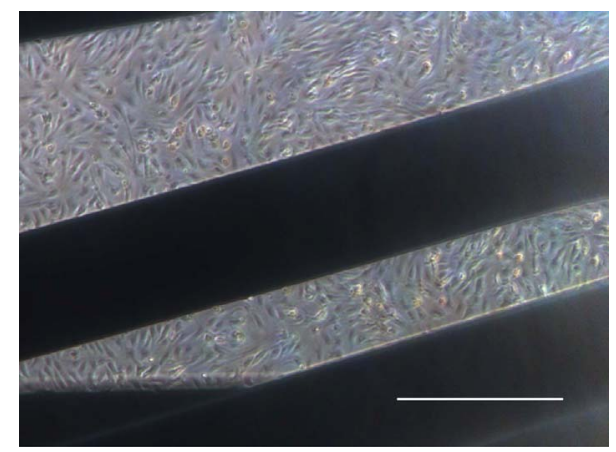

Figure 3. Cell affinity of polyethersulfone hollow fibers. Human chondrocytes $\left(2500\right.$ cells $\left./ \mathrm{cm}^{2}\right)$ were seeded in a culture dish (diameter: $10 \mathrm{~cm}$ ) and cultured in chondrocyte growth medium. Polyethersulfone hollow fibers were placed in the culture dish simultaneously with seeding and co- cultured for one week. The cells grew in contact with the hollow fibers, confirming that the fibers exhibit sufficient cell affinity.

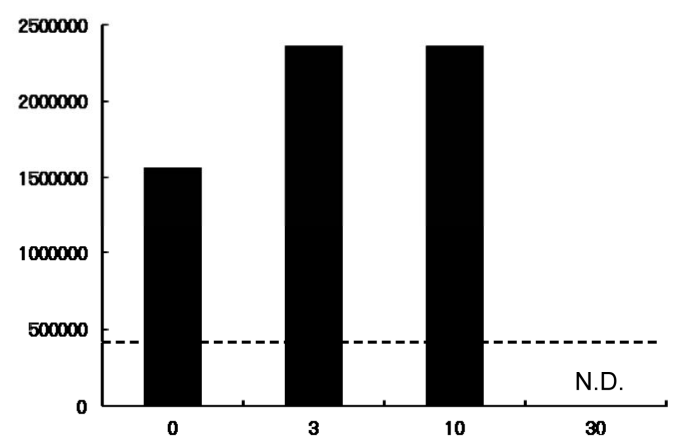

Figure 4. Evaluation of chondrocyte growth in culture using the hollow fiber module. Chondrocytes proliferated for 2 weeks using the hollow fiber module. A mixture of human chondrocytes and atelocollagen $(400,000$ cells $/ 20 \mathrm{~mL}$ ) was injected into ECS, and the flow rate was set at 3,10 , and 30 $\mathrm{ml} / \mathrm{min}$. The growth was compared with that in static culture of a mixture with the same cell number and volume cultured in a dish $(0 \mathrm{~mL} / \mathrm{min})$. At a $30 \mathrm{~mL} / \mathrm{min}$ flow rate, maintenance of circulation was difficult because of the pressure in the hollow fiber module, and no cell growth was observed (ND). The cell growth at a flow rate of 3 - 10 $\mathrm{mL} / \mathrm{min}$ was more favorable than that in static culture.

methods to solve these problems have been proposed. Of these techniques, jar fermenter methods are widely used for the stable mass production of physiological active protein used as a pharmaceutical ingredient [14]. Culture in a hollow fiber module is becoming the mainstream for the production of antibodies as a testing reagent [15].

Generally, hollow fiber modules used for cell culture contain a hollow fiber bundle fixed in cylindrical housing. The inner space of the hollow fibers (lumen) and outer space (ECS) are separated by a sealing material or adhesive, and each space has 2 tube connections (ports) for circulating culture medium or infusing cell suspension. Previous culture modules were developed mainly aiming at culturing recombinant protein-producing cells or hybridoma and collecting proteins secreted by these cells, not considering the harvest of grown cells. We developed the hollow fiber module for culturing cells, mainly adherent cells, with a structure capable of efficiently collecting the grown cells.

In the previous cell cultures using the hollow fibers, some other methods have been also attempted. The hollow fiber surface was coated with cell adhesion-promoting protein, which enabled cells to be cultured on the surface of the hollow fibers [16] In other case, microcarriers were added into ECS to promote cell adhesion to the matrix and subsequent growth [16]. To collect the adhesive cells, they are generally detached by enzyme treatment, such as trypsin, or deionizing treatment with EDTA [17]. However, it is difficult for the treatment solution to diffuse over the whole space containing cells due to the module structure, while the cell recovery rate seems low. Moreover, other problems occur: cells are damaged by treatment. Thus, the use of these methods to harvest cells for medical use should be avoided.

To avoid the cell detachment treatment, we did not adopt a method promoting the adherence of cells to the hollow fiber surface. To collect the adherent cells, we selected the addition of hydrogel into ECS. By disassembling the module into more than 2 parts after the completion of culture, the hydrogel with cells can be easily collected by exposing ECS and scraping and washing out the hydrogel/cells mixture. The cell recovery was facilitated by adding collagenase. Thus, we prepared the hollow fiber module with structures that can be disassembled, aiming at readily removing the content of ECS, and achieved efficient cell recovery.

Since this three-dimensional mass culture of chondrocytes facilitates the mass production with a high performance, it may lead to a breakthrough in regenerative medicine. At present, the regenerative medicine for cartilage has been mainly applied for local defects of joint cartilage. To increase the area of cartilage regeneration and apply it to osteoarthritis, we have to make total number of cultured chondrocytes higher compared with that obtained by conventional culture, and should establish three-dimensional mass culture technique for chondrocytes. Although in the present culture using the hollow fiber module, we enzymatically dissolved collagen gel to collect cells, this collagen gel may serve as a scaffold for chondrocytes $[18,19]$. We prepared the hollow fibers using a non-absorbable material inappropriate for transplantation. However, if hollow fibers can be prepared with an absorbable material, such as biodegradable polymers, hollow fibers containing hydrogel-embedded cells can be taken out and transplanted, which may further facilitate the efficient utilization of cultured cells [20] The hollow fiber module may become an essential tech- 
$\# 1$

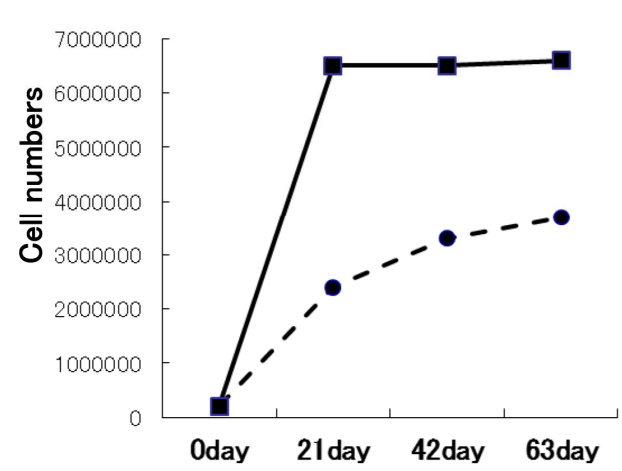

\#2

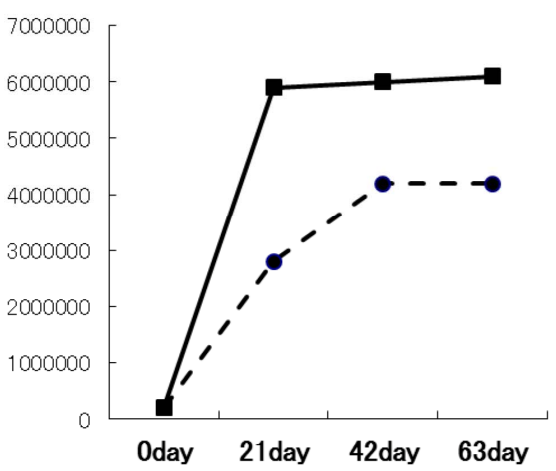

Figure 5. Long-term culture using the hollow fiber module. A mixture of human chondrocytes and atelocollagen was injected into ECS of the hollow fiber module $(400,000$ cells $/ 20 \mathrm{~mL})$, and the flow rate was set at $5 \mathrm{~mL} / \mathrm{min}$. Three sets of the perfusion culture of cells derived from the same patient were prepared, and collected at 21, 42, and 63 days of culture. The growth was compared with those of mixtures with the same cell number and volume statically cultured for the same period in culture dishes (flow rate: $0 \mathrm{~mL} / \mathrm{min}$ ). This experiment was repeated twice (\#1, \#2). Compared to the static cultures, the favorable growth and recovery of cells were achieved by culture using the hollow fiber module (flow rate: $5 \mathrm{~mL} / \mathrm{min}$ ) after 3 weeks of culture.

nique for regenerative medicine, for which further studies may be necessary.

\section{Conclusion}

The hollow fibers were modularized, and a structure to readily harvest cultured cells was added. When we used the hollow fiber module for the three-dimensional culture of chondrocytes, the effective cell growth was confirmed. This three-dimensional culture of chondrocytes seemed to facilitate the mass production with a high performance, which was expected to contribute to the progression of regenerative medicine.

\section{Acknowledgements}

We thank Ms. Yuko Motoki and Mr. Tomoaki Sakamoto for technical support. This work was supported by Grantsin-Aid for Scientific Research from the Ministry of Education, Culture, Sports, Science and Technology of Japan (MEXT, No. 24390451, 24593050, and 25670847), and Research and Development Programs for Self-maturating Device from the New Energy and Industrial Technology Development Organization.

\section{REFERENCES}

[1] S. MacNeil, "Progress and Opportunities for Tissue-Engineered Skin," Nature, Vol. 445, 2007, pp. 874-880. doi:10.1038/nature05664

[2] Y. Z. Jiang, S. F. Zhang, Y. Y. Qi, L. L. Wang and H. W. Ouyang, "Cell Transplantation for Articular Cartilage Defects: Principles of Past, Present, and Future Practice," Cell Transplant, Vol. 20, 2011, pp. 593-607. doi:10.3727/096368910X532738

[3] K. von der Mark, V. Gauss, H. von der Mark and P. Mul- ler, "Relationship between Cell Shape and Type of Collagen Synthesised as Chondrocytes Lose Their Cartilage Phenotype in Culture," Nature, Vol. 267, 1977, pp. 531532. doi:10.1038/267531a0

[4] G. Kretzmer, "Industrial Processes with Animal Cells," Applied Microbiology and Biotechnology, Vol. 59, No. 3, 2002, pp. 135-142. doi:10.1007/s00253-002-0991-y

[5] L. Gillberger, "Emerging Trends in Plasma-Free Manufacturing of Recombinant Protein Therapeutics Expressed in Mammalian Cells," Biotechnology Journal, Vol. 4, No. 2, 2009, pp. 186-201. doi:10.1002/biot.200800241

[6] M. Ochi, Y. Uchio, K. Kawasaki, S. Wakitani and J. Iwasa, "Transplantation of Cartilage-Like Tissue Made by Tissue Engineering in the Treatment of Cartilage Defects of the Knee," The Journal of Bone \& Joint Surgery British, Vol. 84, No. 4, 2002, pp. 571-578. doi:10.1302/0301-620X.84B4.11947

[7] T. Takahashi, T. Ogasawara, Y. Asawa, Y. Mori, E. Uchinuma, T. Takato and K. Hoshi, "Three-Dimensional Microenvironments Retain Chondrocyte Phenotypes during Proliferation Culture," Tissue Engineering, Vol. 13, No. 7, 2007, pp. 1583-1592. doi:10.1089/ten.2006.0322

[8] K. Yonenaga, S. Nishizawa, Y. Fujihara, Y. Asawa, S. Kanazawa, S. Nagata, T. Takato and K. Hoshi, "The Optimal Conditions of Chondrocyte Isolation and Its Seeding in the Preparation for Cartilage Tissue Engineering," Tissue Eng Part C Methods, Vol. 16, No. 6, 2010, pp. 1461-1469. doi:10.1089/ten.tec.2009.0597

[9] Y. Tanaka, T. Ogasawara, Y. Asawa, H. Yamaoka, S. Nishizawa, Y. Mori, T. Takato and K. Hoshi, "Growth Factor Contents of Autologous Human Sera Prepared by Different Production Methods and Their Biological Effects on Chondrocytes," Cell Biology International, Vol. 32, No. 5, 2008, pp. 505-514. doi:10.1016/j.cellbi.2007.12.012

[10] T. Takahashi, T. Ogasawara, J. Kishimoto, G. Liu, H. Asato, T. Nakatsuka, E. Uchinuma, K. Nakamura, H. 
Kawaguchi, T. Takato and K. Hoshi, "Synergistic Effects of FGF-2 with Insulin or IGF-I on the Proliferation of Human Auricular Chondrocytes," Cell Transplant, Vol. 14, No. 9, 2005, pp. 683-693.

doi: $10.3727 / 000000005783982675$

[11] K. Yonenaga, S. Nishizawa, M. Akizawa, Y. Asawa, Y. Fujihara, T. Takato and K. Hoshi, "Utility of NucleoCounter for the Chondrocyte Count in the Collagenase Digest of Human Native Cartilage," Cytotechnology, Vol. 62, No. 6, 2010, pp. 539-545. doi:10.1007/s10616-010-9304-y

[12] S. Satoh, J. Kobayashi, J. Mizoguchi, M. Nogawa and M. Otani, "Serum-Free Cultivation of Anchorage-Dependent Cells on Microcarrier: Effective Production of Human Macrophage Colony-Stimulating Factor," Cytotechnology, Vol. 5, No. 2, 1991, pp. 95-114. doi:10.1007/BF00573882

[13] J. Wu, "Mechanisms of Animal Cell Damage Associated with Gas Bubbles and Cell Protection by Medium Additives," Journal of Biotechnology, Vol. 43, No. 2, 1995, pp. 81-94. doi:10.1016/0168-1656(95)00133-7

[14] B. G. Boedeker, "Production Processes of Licensed Recombinant Factor VIII Preparations," Seminars in Thrombosis and Hemostasis, Vol. 27, No. 4, 2001, pp. 385-394. doi:10.1055/s-2001-16891

[15] D. Wang, W. Liu, B. Han and R. Xu, "The Bioreactor: A Powerful Tool for Large-Scale Culture of Animal Cells," Current Pharmaceutical Biotechnology, Vol. 6, No. 5, 2005, pp. 397-403. doi:10.2174/138920105774370580
[16] M. Takagi, K. Shiwaku, T. Ionue, Y. Shirakawa, Y. Sawa, H. Matsuda and T. Yoshida, "Hydrodynamically Stable Adhesion of Endothelial Cells onto a Polypropylene Hollow Fiber Membrane by Modification with Adhesive Protein," Journal of Artificial Organs, Vol. 6, No. 3, 2003, pp. 222-226. doi:10.1007/s10047-003-0218-8

[17] W. C. Sanford, "A New Method for Dispersing Strongly Adhesive Cells in Tissue Culture," In Vitro, Vol. 10, 1974, pp. 281-283. doi:10.1007/BF02615309

[18] H. Yamaoka, H. Asato, T. Ogasawara, S. Nishizawa, T. Takahashi, T. Nakatsuka, I. Koshima, K. Nakamura, H. Kawaguchi, U. I. Chung, T. Takato and K. Hoshi, "Cartilage Tissue Engineering Using Human Auricular Chondrocytes Embedded in Different Hydrogel Materials," Journal of Biomedical Materials Research Part A, Vol. 78, No. 1, 2006, pp. 1-11. doi:10.1002/jbm.a.30655

[19] H. Yamaoka, Y. Tanaka, S. Nishizawa, Y. Asawa, T. Takato and K. Hoshi, "The Application of Atelocollagen Gel in Combination with Porous Scaffolds for Cartilage Tissue Engineering and Its Suitable Conditions," Journal of Biomedical Materials Research Part A, Vol. 93, 2010, pp. 123-132.

[20] Y. Tanaka, H. Yamaoka, S. Nishizawa, S. Nagata, T. Ogasawara, Y. Asawa, Y. Fujihara, T. Takato and K. Hoshi, "The Optimization of Porous Polymeric Scaffolds for Chondrocyte/Atelocollagen Based Tissue-Engineered Cartilage," Biomaterials, Vol. 31, No. 16, 2010, pp. 45064516. doi:10.1016/j.biomaterials.2010.02.028 